\title{
Trans-cultural aspects of social anxiety disorder and related conditions: a Brazilian case series and a review of international clinical studies
}

\author{
Aspectos transculturais do transtorno da ansiedade social e condições \\ relacionadas: série brasileira de casos e revisão de estudos clínicos \\ internacionais
}

Gabriela Bezerra de Menezes, Leonardo F. Fontenelle e Márcio Versiani

\begin{abstract}
Cross-cultural studies have much to teach clinicians and researchers alike about psychopathology in general and about social anxiety disorder (SAD) in particular. Unfortunately, little is known about the degree and the mechanisms through which cultural environment may influence clinical manifestations of SAD. Objective: Our objective was to identify culture-related clinical patterns in SAD and related disorders. Methods: We described socio-demographic and clinical characteristics of a sample of 62 adult outpatients with SAD seen at a university clinic for anxiety and depressive disorders in Rio de Janeiro, Brazil, and compared them with those reported in clinical samples from North America, Europe, Asia and Oceania identified through a systematic review in Medline, PsychINFO, and LILACS. Results: Our comparison of trans-cultural features of SAD lends partial support to Heimberg's (1997) contention that the majority of socio-demographic features and symptoms of this disorder are relatively independent of geographic and cultural differences. Conclusion: Patients with SAD were almost universally characterized by: 1) a predominance of males in clinical samples; 2) early onset of the disorder; 3) high educational attainment; and 4) great frequency of comorbidities.
\end{abstract}

Key words: social anxiety disorder, clinical description, anxiety disorders, culture, cross-cultural comparison, cultural characteristics.

\section{Resumo}

Estudos transculturais têm muito a ensinar a clínicos e pesquisadores sobre psicopatologia, de modo geral, e transtorno de ansiedade social (TAS) especificamente. Infelizmente pouco se sabe a respeito do grau de influência e dos mecanismos através dos quais o meio cultural pode influenciar as manifestações clínicas do TAS. Objetivo: O presente estudo tem por objetivo identificar padrões clínicos associados à cultura no TAS e transtornos relacionados. Métodos: Foram descritas características clínicas e sociodemográficas de uma amostra de 62 pacientes adultos com TAS acompanhados ambulatorialmente no Programa de Ansiedade e Depressão da Universidade Federal do Rio de Janeiro. Essas características foram comparadas com aquelas de amostras clínicas de América do Norte, Europa, Ásia e Oceania identificadas através de revisão sistemática em Medline, PsychINFO e LILACS. Resultados: Nossa comparação de aspectos transculturais do TAS ratifica parcialmente 0 achado de Heimberg (1997) de que a maioria dos sintomas e das características socioculturais desse transtorno é parcialmente independente de diferenças geográficas e culturais. Conclusão: Pacientes com TAS caracterizaram-se quase universalmente por: 1) predominância de homens nas amostras clínicas; 2) início precoce do transtorno; 3) alto nível educacional; e 4) grande prevalência de co-morbidades.

Palavras-chave: transtorno de ansiedade social, descrição clínica, transtornos de ansiedade, cultura, comparação transcultural, características culturais.

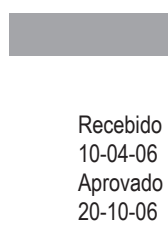

Programa de Ansiedade e Depressão do Instituto de Psiquiatria da Universidade Federal do Rio de Janeiro (IPUB/UFRJ) (Menezes GB, Fontenelle LF, Versiani M)
Correspondence to: Gabriela Bezerra de Menezes

Av. Almirante Ari Parreiras 655/1.207 - Vital Brazil - 24230-321 - Niterói-RJ e-mail: menezesg@globo.com 


\section{Introduction}

There is growing recognition that medical disorders are expressed within the context of particular societies and cultures. It is known that culture can influence significant aspects of certain mental disorders - onset, pathoplasty, course, and outcome - like schizophrenia and bipolar disorders (Trujilo, 2000). Unfortunately, little is known about the degree and the mechanisms through which cultural environment may influence clinical manifestations of social anxiety disorder (SAD).

Constructs such as shyness and embarrassment occur in all cultures, with subtle differences. For example, while in some cultures embarrassment is commonly accompanied by being quiet and silent, in others it may lead to laugh (Edelman, 1989). It seems that SAD also occurs universally, and clinical features are similar in epidemiological studies from different countries (Weissman, 1996).

Cross-cultural perspectives have much to teach about psychopathology in general and about SAD in particular. Stein (2001), for instance, has suggested that an investigation of the similarities and differences between Western SAD and its Japanese equivalent [taijin kyofusho (TKS)] may provide new insights on the influence of cultural factors in the manifestation of SAD. In both conditions the central psychopathological feature is fear of social situations, leading to avoidance behaviors. However, while in the former the fear embarrassing oneself predominates, in the latter the major concern is about offending the others. There is nevertheless a certain degree of overlapping between the two syndromes since it has been demonstrated that $\mathrm{SAD}$ is the most common comorbid disorder among patients with TKS (Matsunaga, 2001).

The objective of this study was twofold: 1) to describe the characteristics of a clinical sample of Brazilian patients with $S A D$; and 2) to compare them with those described in clinical studies from North America, Europe, Asia, and Oceania identified through a systematic review of the literature.

\section{Methods}

\section{Descriptive study}

Sixty-two adult patients with SAD who spontaneously sought treatment in the Anxiety and Depression Research Program of Instituto de Psiquiatria, Universidade Federal do Rio de Janeiro (UFRJ), Brazil, were recruited for this study. Inclusion criteria were: 1) age between 18 and 65 years old; 2) having SAD as the most significant current psychiatric diagnosis; and 3) not suffering from significant medical and neurological disorders. All subjects had their main and comorbid diagnoses established by the main author (GBM) through the use the Structured Clinical Interview for DSM-IV (First et al., 1997).

Patients were also assessed with regard to their sociodemographic and clinical characteristics, including age, gender, age at onset (i.e. age at which patients reported the onset of clinically significant SAD symptoms), mode of onset, course, and subtype of SAD (circumscribed or generalized, as defined by the DSM-IV criteria). The severity of symptoms was assessed using the Clinical Global Impression (CGI).

\section{Systematic review of the literature on international clinical studies}

The identification and selection of articles on SAD was conducted using a method we have first employed in a systematic review of trans-cultural aspects of obsessive-compulsive disorder (Fontenelle et al., 2004).

\section{Inclusion criteria}

Types of studies: we looked for cross-sectional studies that primarily addressed the socio-demographic and clinical features of clinical samples of adult patients with SAD from different countries in three different databases: Medline, PsychINFO and LILACS (a database for Latin-American and Caribbean biomedical studies).

Variables of interest: the following variables were collected from each of the selected studies: 1) country of the study; 2) number of cases; 3) sex ratio (female/male); 4) marital status (\% of married patients); 5) educational level; 6) employment status; 7) mean age at presentation; 8) mean age of $S A D$ onset; 9) rates of the subtypes of $S A D$ according to the DSM-IV criteria (circumscribed or generalized subtype); 10) severity of SAD; and 11) main psychiatric comorbidities.

\section{Exclusion criteria}

We excluded: 1) case reports, letters to the editor, and reviews; and 2) studies in which less than $50 \%$ of the variables of interest were reported.

\section{Search strategies}

We performed an electronic search in Medline using the following combination of medical subject heading (MeSH) terms: social phobia (MeSH Major Topic) AND (culture [MeSH Major Topic] OR crosscultural comparison [MeSH Major Topic] OR cultural characteristics [MeSH Major Topic] OR socioeconomic factors [MeSH Major Topic] OR developing countries [MeSH Major Topic] OR ethnology [MeSH Major Topic]). We also systematically explored the related articles function of Medline for each relevant found reference.

Latin American studies were searched in LILACS. Given the relatively small number of references contained in this database, we were able to use a widened search strategy, reviewing all studies published under the MeSH term social phobia.

For all searches, the probed period began at the earliest available date and ended in February 2004. The reference lists of retrieved articles were further scanned for additional relevant papers.

\section{Results}

\section{Descriptive study}

The socio-demographic and clinical characteristics of our sample are shown in the leftmost column of Table 1.

\section{Systematic review}

We found a total of 46 studies in Medline, of which only four fulfilled our inclusion criteria: Chaleby and Raslam (1990), Heimberg et al. (1997), Matsunaga et al. (2001) and Gökalp et al. (2001). No additional articles were identified, neither through the related articles (RAs) function of Medline nor by the PsychINFO and the LILACS searches. A summary of studies we identified (comprising six different international samples) is shown in Table 1. 
Table 1. Cross-national comparison of socio-demographic and clinical presentation in clinical samples of adult patients with social anxiety disorder

\begin{tabular}{|c|c|c|c|c|c|c|c|}
\hline Region & South America & $\begin{array}{l}\text { North } \\
\text { America }\end{array}$ & Europe & Oceania & Near-East & Middle-East & Far-East \\
\hline Studies & $\begin{array}{l}\text { Menezes et al. } \\
(2004)\end{array}$ & $\begin{array}{l}\text { Heimberg } \\
\text { et al. (1997) }\end{array}$ & $\begin{array}{l}\text { Heimberg } \\
\text { et al. (1997) }\end{array}$ & $\begin{array}{l}\text { Heimberg et al. } \\
\text { (1997) }\end{array}$ & $\begin{array}{l}\text { Gökalp et al. } \\
\text { (2001) }\end{array}$ & $\begin{array}{l}\text { Chaleby and } \\
\text { Raslam (1990) }\end{array}$ & $\begin{array}{l}\text { Matsunaga } \\
\text { et al. (2001) }\end{array}$ \\
\hline Country & Brazil & USA & Sweden & Australia & Turkey & Saudi Arabia & Japan \\
\hline Number of cases & 62 & 123 & 80 & 51 & 87 & 80 (males) & 48 \\
\hline $\begin{array}{l}\text { Sex ratio (female/ } \\
\text { male) }\end{array}$ & 0.51 & 0.84 & 4 & 0.96 & 0.27 & Male sample & 1.53 \\
\hline $\begin{array}{l}\text { Marital status } \\
(\% \text { married })\end{array}$ & 45 & $\begin{array}{l}\text { Women: } 51.7 \\
\text { Men: } 43.1^{*,{ }^{* *}}\end{array}$ & $\begin{array}{l}\text { Women: } 51.7 \\
\text { Men: } 43.1^{*},{ }^{* *}\end{array}$ & $\begin{array}{l}\text { Women: } 51.7 \\
\text { Men: } 43.1^{*},{ }^{* *}\end{array}$ & 26.4 & 47 & 15 \\
\hline \multirow[t]{4}{*}{$\begin{array}{l}\text { Educational } \\
\text { level }(\%)\end{array}$} & Primary: 16 & Tertiary: 69.9 & Tertiary: 32.5 & Tertiary: 25.5 & $\begin{array}{l}\text { Elementary } \\
\text { school: } 13.8\end{array}$ & $\begin{array}{l}\text { Grades 1-6: } 10 \\
\text { Grades 7-12: } 41\end{array}$ & $\begin{array}{l}12.4(2) \\
\text { educational years }\end{array}$ \\
\hline & Secondary: 42 & & & & Middle school: 9.2 & College: 49 & \\
\hline & Tertiary: 42 & & & & Secondary: 35.6 & & \\
\hline & & & & & Tertiary: 41.4 & & \\
\hline $\begin{array}{l}\text { Employment } \\
\text { status }\end{array}$ & $61 \%$ employed & NA & NA & NA & $55.2 \%$ employed & $\begin{array}{l}14 \% \text { student } \\
78 \% \text { employed }\end{array}$ & NA \\
\hline Age (years) & $38.61( \pm 10.6)$ & $36.3( \pm 9.9)^{\star *}$ & $36.3( \pm 9.9)^{\star *}$ & $36.3( \pm 9.9)^{\star *}$ & $26.2( \pm 8.5)$ & $\begin{array}{l}\text { Between } 20-29 \\
\text { years: } 76 \%\end{array}$ & $25.5(6.3)$ \\
\hline $\begin{array}{l}\text { Age of onset } \\
\text { (years) }\end{array}$ & $16.8( \pm 16.8)$ & NA & NA & NA & $16.2( \pm 7.1)$ & $\begin{array}{l}\text { Onset before } 19 \\
\text { years: } 72.5 \%\end{array}$ & $18( \pm 3.3)$ \\
\hline \multirow[t]{2}{*}{$\begin{array}{l}\text { Type of SAD } \\
\text { (DSM-IV) }\end{array}$} & $\begin{array}{l}\text { Generalized: } \\
90.3 \%\end{array}$ & NA & NA & NA & $\begin{array}{l}\text { Generalized: } \\
80.5 \%\end{array}$ & NA & NA \\
\hline & $\begin{array}{l}\text { Circumscribed: } \\
9.7 \%\end{array}$ & & & & $\begin{array}{l}\text { Circumscribed: } \\
19.5 \%\end{array}$ & & \\
\hline $\begin{array}{l}\text { Severity of SAD } \\
\text { (CGI) }\end{array}$ & $5.15( \pm 0.74)$ & NA & NA & NA & NA & NA & NA \\
\hline \multirow[t]{3}{*}{$\begin{array}{l}\text { Comorbidities } \\
\text { (main) }\end{array}$} & MDD: $41.9 \%$ & NA & NA & NA & $\begin{array}{l}\text { Dysthymia: } \\
16.1 \%\end{array}$ & NA & SAD: $38 \%$ \\
\hline & $\begin{array}{l}\text { Alcohol abuse: } \\
19.4 \%\end{array}$ & & & & PD: $12.6 \%$ & & MDD: $27 \%$ \\
\hline & PD: $9.7 \%$ & & & & $\begin{array}{l}\text { Agoraphobia: } \\
10.3 \%\end{array}$ & & DD: $15 \%$ \\
\hline $\begin{array}{l}\text { Diagnostic } \\
\text { assessment }\end{array}$ & SCID & ADIS-R & ADIS-R & ADIS-R & SCID & MMPI & SCID \\
\hline
\end{tabular}

*Values not available for the whole sample; **values not available for samples individually; NA: not available; MDD: major depressive disorder; PD: panic disorder; SAD: social anxiety disorder (according to the DSM-IV); DD: delusional disorder; SCID: Structured Clinical Interview for DSM; ADIS-R: Anxiety Disorders Interview Schedule Revised; MMPI: social withdrawal scale of the Minnesota Multiphasic Personality Inventory.

\section{Discussion}

This study was an attempt to investigate whether sociodemographic and clinical features reported in international clinical samples of individuals with SAD and related disorders would differ from each other. Our approach consisted in comparing our Brazilian clinical sample of SAD with treatmentseeking samples from other countries. The patterns of regularity and the inconsistencies identified through these comparisons were the objects of our analysis.
We found that clinical samples of adult SAD were almost universally characterized by a predominance of males. Although women receive a diagnosis of SAD more frequently in epidemiological studies, a higher prevalence of males is often observed in treatment-seeking samples (Stein, 1997; Lang, 2001). The predominance of male patients with SAD in our study is similar to what has been described in clinical samples from the US, Australia, and Turkey. These patterns may reflect a greater cultural expectation concerning social performance of men, leading to more elevated degrees of 
perceived distress and impairment (Weinstock, 1999). The Swedish and the Japanese clinical samples, however, included a greater percentage of women (female/male ratio of 4 and 1.53 , respectively). It is conceivable, therefore, that in those countries some still unidentified socio-cultural factors could stimulate treatment-seeking behavior preferentially in women rather than in men (Heimberg et al., 1997). The Saudi Arabian sample was composed only by males, a finding that possibly reflects the peculiar position of women in this society.

The three samples presented by Heimberg et al. (1997) differed in terms of marital status, with a greater proportion of Swedish subjects being married, but when analyses of marital status were conducted separately for each gender, no group differences emerged. In contrast, Turkish and Japanese subjects were predominantly unmarried $(73.6 \%$ and $85 \%$, respectively), a finding that may reflect the lower average age of these samples. A more balanced marital status was reported in the Brazilian and the Saudi Arabian samples.

Heimberg et al. (1997) found cross-national differences in educational attainment (with higher levels observed in the American sample and lower in the Swedish one) and suggested that they may be related to base-rate differences in these countries. All the groups, however, were highly educated, challenging the classical association between SAD and poor academic achievement (Wittchen and Fehm, 2001). The educational attainment observed in our sample $(42 \%$ of our volunteers had some higher education) was by far superior to the average number of years of schooling in Brazil (5.7 years). One could speculate that a higher educational level could lead to greater expectations concerning social performance, resulting in greater distress and more frequent treatment-seeking behavior. Besides, being more educated might facilitate the access to information about SAD and its treatment. These suggestions are consistent with those of Wifley et al. (2001), who found that individuals with low educational levels tend not to seek mental health treatment, regardless of their diagnosis.

The high rates of comorbidity observed in the Turkish and in the Brazilian samples are consistent with those observed in most clinical and epidemiological studies. However, the main type of comorbid depressive syndrome differed in the two samples. Among Brazilian subjects, major depressive disorder predominated, while in the Turkish sample dysthymia was the most frequently found mood disorder. Another significant difference lied in the pattern of pathological alcohol consumption. While in the Brazilian sample alcohol abuse was the second most common comorbidity $(19,4 \%)$, it was found in only $2.3 \%$ of the Turkish subjects. We believe that this finding may reflect differences in terms of religious beliefs and practices (i.e. the Islamic forbiddance of alcohol consumption).

A chart review of 48 patients diagnosed with TKS revealed that this condition consistently overlaps with the DSM-IV concept of SAD (Matsunaga et al., 2001), with 38\% of the sample fulfilling diagnostic criteria for both conditions. However, we found that individuals with TKS were younger and more often single. Furthermore, a significant minority (15\%) of these patients exhibited no insight concerning their symptoms and, in consequence, met the DSM-IV diagnostic criteria for delusional disorder, somatic type. Given the relatively high frequency of this finding among individuals with TKS, one could question whether the inclusion of a poor insight subtype of SAD is warranted. According to the DSM-IV, the existence of a poor insight subtype of certain anxiety and somatoform disorders (such as obsessive-compulsive disorder and body dysmorphic disorder) is already recognized.

Our comparison of trans-cultural features of SAD lends partial support to Heimberg's (1997) contention that the majority of clinical and socio-demographic features of this disorder are relatively independent of geographic and cultural influences. Most discrepancies found in these domains probably reflect recruitment bias, conceptual uncertainties or lack of standardization of assessment procedures (Fontenelle et al., 2004). However, further studies with similar recruitment procedures of demographically matched samples from different cultures, ethnic backgrounds, and national origins are required in order to definitely ascertain whether the found differences reflect cultural influences.

We were not able to compare some potentially interesting trans-cultural aspects of SAD because of the lack of a systematic investigative approach in most international studies. Important features, such as the content of symptoms, subtype, comorbidity rates and clinical course, were not described in several samples. $A$ standardized package for the assessment of patients with SAD is required in order to provide a more thorough understanding of the role of cultural differences in the clinical presentation of SAD.

\section{References}

American Psychiatric Association. Diagnostic and Statistical Manual of Mental Disorders. $4^{\text {th }}$ ed. Washington (DC): American Psychiatric Association; 1994.

Chaleby KS, Raslam A. Delineation of social phobia in Saudi Arabians. Soc Psychiatry Psychiatr Epidemiol, 25(6): 324-7, 1990.

Edelmann RJ, Asendorf J, Contarello A et al. Self-reported expression of embarrassment in five European cultures. J Cross-Cultural Psychol, 20: $371-375,1989$
First MB, Spitzer RL, Gibbon M et al. Structured Clinical Interview for DSM-IV Axis I Disorders, Research Version, Patient Edition (SCID-I/P). New York: Biometrics Research, New York State Psychiatric Institute; 1997.

Fontenelle FL, Mendlowicz MV, Marques C, Versiani M. Trans-cultural aspects of obsessive-compulsive disorder: a description of a Brazilian sample and a systematic review of international clinical studies. J Psychiatric Research, 38(4), 403-11, 2004.

Gökalp PG, Tükel R. Solmaz D, Demir T, Kiziltan E, Demir D, Babaoðlu 
NA. Clinical features and co-morbidity of social phobics in Turkey. Eur Psychiatry, 16: 115-21, 2001

Heimberg RG, Makris GS, Juster HR, Öst L-G, Ronald M, Rapee RM. Social phobia: a preliminary cross-national comparison. Depress Anxiety, 5: 130-3, 1997

Lang AJ, Stein MB. Social phobia: prevalence and diagnostic threshold. J Clin Psychiatry 62(suppl 1): 5-10, 2001.

Matsunaga H, Kiriike N, Matsui T, Iwasaki Y, Stein DJ. Taijin kyofusho: a form of social anxiety disorder that responds to serotonin reuptake inhibitors? Int J Neuropsychopharmacol, 4(3): 231-7, 2001.

Stein DJ, Matsunaga $\mathrm{H}$. Cross-cultural aspects of social anxiety disorder. Psychiatr Clin North Am, 24(4): 773-82, 2001.Stein MB. Phenomenology and epidemiology of social phobia. Int Clin Psychopharmacol, 12(suppl 6): S23-S26, 1997.
Trujilo M. Cultural psychiatry. In: Sadock BJ, Sadock VA, editors. Kaplan \& Sadock's Comprehensive Textbook of Psychiatry. $7^{\text {th }}$ ed. Lippincott Williams and Wilkins, p. 492-9, Philadelphia, 2000.

Weinstock LS. Gender differences in the presentation and management of social anxiety disorder. J Clin Psychiatry, 60(suppl 9): 9-13, 1999.

Weissman MM, Bland RC, Canino GJ et al. The cross-national epidemiology of social phobia: a preliminary report. Int Clin Psychopharmacol, 11(suppl): 9-14, 1996.

Wiffley DE, Pike KM, Dohm FA, Striegel-Moore RH, Fairburn CG. Bias in binge eating disorder: how representative are recruited clinic samples? J Consult Clin Psychol, 69: 383-388, 2001.

Wittchen $\mathrm{H}-\mathrm{U}$, Fehm H. Epidemiology, patterns of comorbidity, and associated disabilities of social phobia. Psychiatr Clin North Am, 24(4): 617-41, 2001 